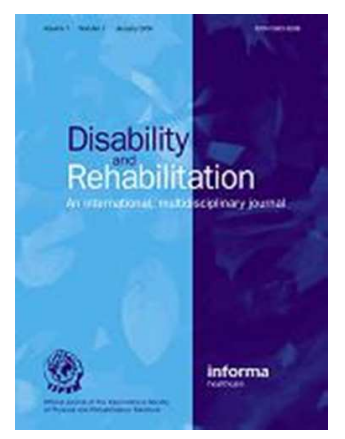

\title{
CHALLENGES TO PROVIDING HIV PREVENTION EDUCATION TO YOUTH WITH DISABILITIES IN SOUTH AFRICA
}

\begin{tabular}{|r|l|}
\hline Journal: & Disability and Rehabilitation \\
\hline Manuscript ID: & TIDS-01-2011-038.R1 \\
\hline Manuscript Type: & Research Paper \\
\hline Keywords: & HIV/AIDS, Adolescents, South Africa, HIV prevention, Health education \\
\hline
\end{tabular}

SCHOLARONE ${ }^{\text {IM }}$

Manuscripts 


\title{
CHALLENGES TO PROVIDING HIV PREVENTION EDUCATION TO YOUTH WITH DISABILITIES IN SOUTH AFRICA
}

\begin{abstract}
Purpose: In South Africa, little is known how HIV prevention education is implemented in schools for learners with disabilities. This article reports on findings from a study exploring the extent to which HIV education is reached by people with disabilities in South Africa, and the challenges faced by educators providing HIV prevention education to learners with disabilities.

Method: A survey questionnaire completed by 34 schools for learners with special education needs in the Western Cape province of South Africa. Additional complimentary data was collected through interviews with a total of 21 members of staff at schools for learners with disabilities.

Results: Respondents recognise the importance of providing HIV prevention education for people with disabilities. Staff report some challenges in providing HIV prevention education: barriers to communication; discomfort about issues of sexuality and disability; disagreements among staff about what is appropriate content for sexual health education, and fears of promoting sexual activity.

Conclusions: There is a need for HIV prevention education to be specifically customized to the needs of the specific population. A general programme, which is included as part of a general curriculum and generally tailored to "mainstream" schools, would need to be adapted according to specific needs and disabling barriers faced.
\end{abstract}


KEYWORDS: HIV/AIDS; adolescents; HIV prevention; South Africa; health education

Word count: 4141 excl references and tables 


\section{CHALLENGES TO PROVIDING HIV PREVENTION EDUCATION TO YOUTH WITH DISABILITIES IN SOUTH AFRICA}

\section{INTRODUCTION}

People with disabilities have until fairly recently been largely overlooked with regards to combating the HIV epidemic. The international literature suggests that people with disabilities may be at increased risk for HIV infection, yet are often excluded from general HIV prevention campaigns [1-3]. This article reports on findings from a study exploring challenges to providing HIV prevention education to youth with disabilities in South Africa.

In South Africa, among one of the most affected regions in the world, little is known about how HIV/AIDS affects people with disabilities, although there is now a small but growing body of research in this area. Historically, people with disabilities were often perceived as being asexual, and thus not in need of sex education [4]. There is often considerable anxiety about the sexuality of people with learning disabilities in particular, where they are often infantilized; perceived as forever children and thus not in need of sex education [5]. Alternatively people with learning disabilities may also be constructed as being "oversexed" or sexually disinhibited [5]. In such cases sex education can be seen as potentially problematic as it is feared that it would encourage sexual expression.

Furthermore, there are often concerns about vulnerability to sexual exploitation [6], and so carers and parents may be anxious about the topic of sex and sexuality with regards their child with disability [7]. In South Africa, the few studies which have been 
conducted suggest that knowledge about HIV/AIDS among people with disabilities is low [8-9]. Findings from other parts of the world suggest that people with disabilities have lower levels of HIV-related knowledge compared to the general population [10-11]. A recent survey of disability organisations in South Africa highlighted the perception that people with disabilities were excluded from general HIV prevention programmes [12]. The lack of HIV prevention education is a worrying issue, given the suggested increased vulnerability for HIV infection, and reports of unsafe sexual practices among some people with disabilities in South Africa [13], as in other parts of the world [14-16]. Eide and colleagues [17] have shown that access to HIV prevention related information for people with disabilities is predicted by gender, geographical location and level of education. The level of knowledge may also depend on the severity of disability [18-19]. Eide and colleagues [17] have further shown that level of HIV prevention information predicts access to voluntary counselling and testing for HIV for people with disabilities. Thus education is an important component of HIV prevention for people with disabilities, as it is with the general population.

In South Africa, HIV prevention education forms part of the national curriculum for schools. A study was conducted evaluating the implementation of this HIV/AIDS prevention programme at secondary schools in South Africa [20]. Visser and colleagues' [20] evaluation suggested that this programme was not implemented successfully across schools. They reported that many schools were experiencing limited resources and were finding it difficult to prioritise HIV/AIDS when faced with many pressing social problems. Few studies explore the implementation of HIV prevention education at 
schools for disabled learners in South Africa. Kelly and colleagues [21] reported that HIV prevention education at schools for people with disabilities may only be done sporadically at times when an issue of sexuality with a student arises. Rohleder and Swartz [7] explored the anxieties expressed among educators working with people with learning disabilities (who represented some of the participants in the study reported on in this article). They found how the educators who were interviewed had feelings of ambivalence and conflict about recognising the need to provide sex education, while doing so in a manner that does not promote sexual activity.

In order to begin to address some of the barriers faced by people with disabilities in accessing HIV prevention education, it is important to know what the challenges are to providing such education. This paper reports on a study exploring the provision of safe sex education among Schools for Learners with Special Education Needs (LSEN schools) in the Western Cape Province of South Africa. The study aimed to explore the extent to which safe sex education is being provided to young people with disabilities, and the possible challenges that educators face in providing safe sex education.

\section{METHOD}

The study employed a mixed method design, using both a survey and interview method for collecting data. For the survey the study made use of a slightly modified version of the questionnaire developed and used in the World Bank/Yale University Global Survey on HIV/AIDS and Disability [22]. The questionnaire includes both closed and openended questions, and focused on HIV awareness, the provision of HIV prevention 
programmes by the schools themselves as well as knowledge of other HIV prevention programmes aimed at people with disabilities, and questions about support and services available for people with disabilities living with HIV. The questionnaire was in English, as this is the most commonly used language in South Africa. The survey questionnaire was sent to a total of 64 LSEN schools, representing all LSEN schools in the Western Cape Province in South Africa, as listed by the Department of Education. The questionnaire was initially sent by email or post. The questionnaire was sent to the principal of the school, and a covering letter suggested that a member of staff most familiar with the school's HIV prevention education provision should be asked to complete the questionnaire. Response rates to mail surveys in particular tend to be poor. So suggestions for improving response rates were followed: The questionnaire was sent with a covering letter which included the logos of the two institutions involved and a self addressed and stamped envelope; a second round of questionnaires was sent, which was followed up with reminder emails [23]. As response rates remained poor, a third posting of the questionnaire was made, and where possible this was delivered and collected in person. A total of 34 schools responded to the survey, resulting in a 53\% response rate.

Further complimentary data were collected by means of a qualitative study, involving individual and focus group interviews with people involved in providing HIV prevention education at schools for learners with disabilities. Participants were recruited by means of convenient sampling by approaching 3 organisations:

- An organisation supporting schools for learners with learning disabilities, who had recently developed an HIV prevention education programme. From this organisation, 
a manager and 2 facilitators of the education programme were interviewed individually. One person involved in providing HIV prevention education at a residence for young adults with learning disabilities was also interviewed. A further 3 teachers (working at two different schools) were recruited and interviewed in a focus group interview.

- A school for learners with visual disabilities, where individual interviews were conducted with the two deputy principals, the nurse and the psychologist, as well as a focus group interview with four teachers.

- A school for learners with Cerebral Palsy, where individual interviews were conducted with 2 nurses. Two hostel care workers were interviewed as a pair at their request, and a focus group interview was conducted with 3 teachers.

There was thus a total of 21 participants interviewed either individually or as part of a group interview. The duration of the interviews were between 1 and $1 \frac{1}{2}$ hours and were tape recorded and transcribed. The interviews were semi-structured, guided by an interview schedule of questions focusing on educators' experiences in providing HIV prevention; challenges faced and supportive structures. Questions also focused on perceptions of HIV risk for people with disabilities.

Quantitative data from the survey study was analysed using descriptive statistics, with the aid of SPSS. Qualitative data from the survey as well as the interview transcripts were analysed using thematic analysis [24]. The qualitative data were coded according to themes, which were both partly informed by the focus of the questions asked, as well as from what emerged in the data. Quotes from the questionnaires and transcripts were 
selected and grouped according to emerging themes. This process was done manually, without the aid of computer software. Representative quotes are presented here to illustrate the various themes.

Prior to commencement of the study, ethical approval was sought and granted by the institutional ethics bodies, as well as the Western Cape Department of Education. All participants gave their informed consent prior to taking part. Any limits to anonymity in the reporting of data in the cases where schools could be identifiable due to the specific disability of their learners, were discussed beforehand.

\title{
RESULTS
}

There is a small majority response rate to the survey. Furthermore, the survey sample is representative of all disability groups (Table 1).

\section{INSERT TABLE 1 HERE}

\section{Awareness and Perceptions of HIV risk for people with disabilities}

\begin{abstract}
All survey respondents and interview participants felt that people with disabilities were at risk for HIV infection, with 31 (of 34) expressing that people with disabilities were at increased risk for HIV infection. The reason given for why people with disabilities were at risk is that people with disabilities are sexually active and thus at equal risk for HIV infection, as their non-disabled peers. The most frequently mentioned perceived risk factors were vulnerability to sexual abuse and general lack of information about HIV,
\end{abstract}


which may place people with disabilities at increased risk for HIV. Survey respondents had very little information as to the prevalence of HIV and AIDS among their student body. Only 5 (of 34) respondents indicated that they had some knowledge about learners who were HIV-positive, but none of the respondents had any sorts of statistical data as to prevalence.

\section{Provision of HIV prevention education}

All schools reported that they were providing some HIV prevention education. This formed part of the core national curriculum and was delivered in a subject called "life orientation", which included topics on HIV/AIDS and other sexually transmitted diseases, safe sex, substance use and other relevant topics, such as relationships and sexual abuse. Survey respondents were asked to give some details as to their HIV prevention programme. While most (31 of 34) gave some information, this varied from quite brief and lacking in detail (for example comments such as "part of life orientation"), to more elaboration. It is difficult to get a sense of the quantity and quality of HIV prevention education provided, but answers suggest that this was provided regularly. For example one respondent wrote:

\footnotetext{
We do it actually once a week; it's included in the syllabus. It differs in the time fare for each educator, but we do it once a week with the learners... Mine is on a Monday. I spend a Monday just on HIV/AIDS. We have the booklets we got from the department and the box with the dolls and whatever. We follow a program. I also use the HIV counselor book. The first quarter I did "What is HIV" again
} 
because children with disabilities tend to forget things, so we went back to the basics (Survey respondent; school for learning disabilities)

However, teachers interviewed at a school for learners with cerebral palsy suggested that such sex education was done sporadically. For example one of these teachers stated:

Only when a teacher approaches me to say look I have a problem in the class and I feel as a teacher uncomfortable to talk to the children about it. Will you come and talk to the children? And that happens once in a blue moon. (Interview participant; school for learners with cerebral palsy)

\begin{abstract}
Most schools (25 out of 34) also asked for help with HIV prevention programmes, with a majority suggesting Government departments, typically the Department for Social Services (23 out of 34) and the Department of Education (13 out of 24) as sources for support. While all schools were providing HIV prevention education, many survey respondents felt that people with disabilities were partly excluded from the general HIV prevention programmes and media campaigns. Most respondents felt that people with disabilities were being reached by HIV prevention messages meant for the general population, however almost half (15 out of 31$)$ indicated that they were only partly reached or not at all (Table 2).
\end{abstract}

INSERT TABLE 2 HERE 
With regards the amount of HIV prevention information reached by people with disabilities, half (17 out of 33) of the survey respondents indicated that it was less than that reaching the general population. Respondents were asked to select from a list of possible reasons why general HIV prevention programmes were inaccessible to people with disabilities. Reponses are presented in Table 3.

\title{
INSERT TABLE 3 HERE
}

\begin{abstract}
However, most felt that the information that people with disabilities were receiving was as accurate as that reaching the general population (18 out of 32 respondents) or even more accurate ( 5 out of 32 ) when considering their HIV prevention programmes, and 6 (out of 32) felt that the general information received by people with disabilities was less accurate.
\end{abstract}

\section{Challenges in providing HIV prevention education}

Most survey respondents did not report many challenges in providing sex education to youth with disabilities, but the few noted were explored further in the individual and focus group interviews.

\section{Barriers to "getting the message across"}

A third of respondents (11 out of 34) felt that people with disabilities did not have a high sense of risk, and that they (the learners) saw HIV as not a priority issue for them. As many of the learners come from disadvantaged backgrounds, from areas of Cape Town 
where unemployment, poverty and gangsterism are rife, the lack of prioritisation of HIV can be seen in the light of other more pressing social issues. Teachers at a school for learners with cerebral palsy reflected on what learners seemed to think:

Teacher 1: The majority of our kids they've got to deal with violence and death every single day, so HIV is not high on their agenda. What's high on their agenda-

Teacher 2: -Survival is high on their agenda

Other respondents commented that their learners had a reduced capacity to understand HIV prevention messages. For example one respondent wrote:

sometimes the language is too complex. It needs to be slow. Our kids language is very pedantic; they take things very literally, so if it is too metaphorical they don't quite get the message (Survey respondent; School for Deaf or hard of hearing)

This was most often stated in relation to people with learning disabilities. One interview participant compared the challenge he faced when he first started providing HIV prevention education for people with learning disabilities to previous "mainstream" education:

when I had to be involved with a specific group of people, intellectually disabled people, it was quite a challenge for me. And struggling a bit to be able to 
understand and taking things for granted, saying things, a lot of words, not knowing that words get confused with words and concepts (Interview participant; school for learning disabilities)

Responses indicated that many schools have been provided with teaching materials for safe sex education. Survey respondents and interview participants referred to teaching aids such as workbooks, anatomical dolls, and pictures. This was not the case for all schools, where materials were not provided, or were seen as inappropriate. For example, teachers interviewed at a school for learners with cerebral palsy spoke about how they had been waiting for workbooks for over two years, and they had still not arrived. Written material was regarded as problematic, where people with learning disabilities were unable to read:

Well we had a problem with the curriculum. The one we do have now is on a much simpler level but I would say those pamphlets are still too much reading for them and most of our learners can't read; they need pictures. They need something like a play (Survey respondent; school for learning disabilities)

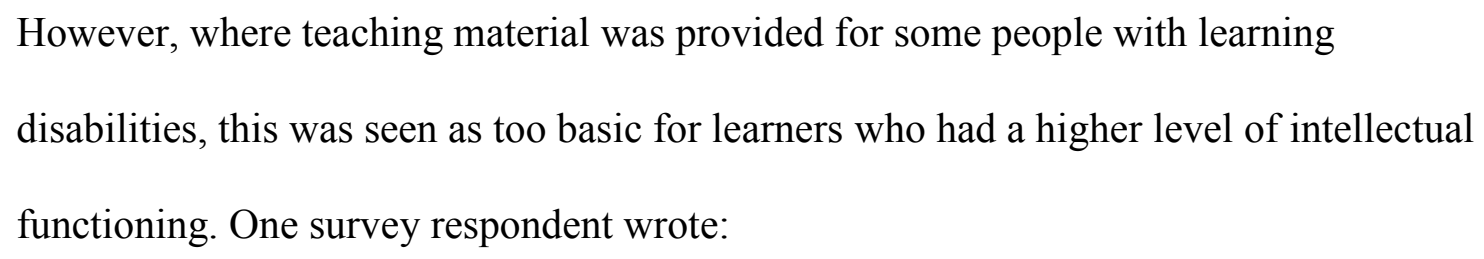


We've got quite a few games the department gave us. A lot of them are extremely basic. We have kids with learning problems, but verbally they are very strong. So if I can read the question to them, if they struggle to read, they can answer very, very well, and they were quite insulted by some of the games. They said it was far too easy. We tried to play a game one day and we had to stop because they lost complete interest in it. A lot of the material is targeted at low learners. This is why educated people say “this can't happen to me; this only affects stupid people” (Survey respondent; “other” disabilities)

This was echoed by one of the interview participants:

because all the resources, everything for mainstream is impossible to do with learners with intellectual disabilities. You see learners in the senior phase, being stuck with books of the grade one, grade two level, which is basically colouring in pictures (Interview participant; school for learning disabilities)

A few commented on the difficulty of teaching about HIV, when HIV is not a visible disease. This makes it an 'abstract' concept which is difficult to understand for some.

It is difficult to show the children how a person looks if they have HIV because it's not like it's an arm that's off or something physical. It is difficult for them to understand. They don't understand the concept of 5 or 7 years because it does not affect them now (Survey respondent; school for multiple disabilities) 
Embarrassment, discomfort and lack of confidence

One survey respondent wrote about how it was difficult to teach sex education, as it immediately sparked embarrassment and laughter among learners:

we have books and visual material, but sometimes the books are not appropriate. They can't all read and the pictures are very explicit, so you can't focus on what you want to do with them because now they are all laughing because they see the private parts, so the focus is all off (Survey respondent; school for multiple disabilities)

This was echoed by interview participants who spoke of their own sense of embarrassment in teaching a topic that many found to be explicit:

Another difficult area to teach about is that actual sexual act. How do you teach about the actual sexual act? [...] So now I've made lots of these little cut out characters. And I got them clothed in underwear and naked. Now it is possible to show sexual positions with that or maybe a little bit of sexual touching without, but again it does feel crossing the line somewhere and I don't know whether that's just my personal embarrassment (Interview participant - school for learning disabilities) 
This embarrassment and discomfort seemed to deter teachers from actually providing the sex education:

I actually find it very challenging to get through to them. We don't have the same, I want to say, background, because when you start off with something, you will find them looking at one another and laughing and having this - because they are used to totally different wording of a thing or totally different situation. So I will just do it incidentally [...] if someone brings it up. I don't make a formal lesson of it, because then you get derailed totally, because it's a joke and it's a laughing (Interview participant - school for learners with cerebral palsy)

\begin{abstract}
Related to this sense of embarrassment and lack of confidence is the sense of feeling illprepared for the challenge. Participants were not specifically asked about the training that they received, but one person commented:
\end{abstract}

We try our best to adapt the programs ourselves, but there is really not a program for the disabled people. We get training, but it is six weeks and that's it; no follow-ups. So it is difficult to get into the community and train other people because my knowledge is so limited (Survey respondent; school for multiple disabilities)

Disagreements among staff about HIV prevention 


\begin{abstract}
Many of the interview participants spoke of disagreements among staff about the provision of sex education and HIV prevention programmes. This was particularly the case as participants recalled the early days of starting sex education at LSEN schools:
\end{abstract}

\begin{abstract}
When I got here there was quite a dilemma and a need was felt at the time, I don't really know why, to promote certain things like HIV and the use of condoms. The principal at that time was - because I was quite upset when I found out that condoms weren't freely available to them, so I actually implemented it, and said, you know, "see that there are condoms available. Why can't they use it? And why isn't it freely available?" And the principal at that time wasn't very keen on this. I just ignored him and I just went ahead [...] he felt that giving the children condoms we actually tell them to have sex; we're promoting sex (Interview participant - schools for learners with visual disabilities)
\end{abstract}

\begin{abstract}
One staff member at a school for learners with visual disabilities spoke of continuing disagreements, where some staff members refused to do any teaching around sex education, leaving it as the responsibility of others:
\end{abstract}

They refused to give certain parts of the life orientation, or teach it. They would want me to do certain parts, and they would only do the one's they feel comfortable with. Which resulted in me doing the bulk of the life orientation (Interview participant; school for learners with visual disabilities) 


\section{DISCUSSION AND CONCLUSION}

This study explored the extent to which HIV prevention education was being provided by schools for people with disabilities in the Western Cape Province of South Africa. The results indicate that staff at schools recognise the risks for HIV infection among people with disabilities and the need to provide HIV prevention education. While most respondents felt that people with disabilities were being reached by general HIV prevention programmes, the amount of information that was being reached was less than that of the general population. However, all of the schools surveyed were providing HIV prevention education as part of the national curriculum.

In our study, while survey respondents gave little elaboration on the success or otherwise of their HIV prevention education, there is some indication, particularly from the interviews with staff, that teachers face some substantial challenges to providing HIV prevention education. The most frequently cited challenges related to difficulties in conveying HIV prevention messages in a way that would be accessible and understandable to the disabled learners. This presents a particular challenge in teaching people with disabilities. Respondents in the survey commented on the complexity of information, not suitable for people with learning disabilities in particular. Other barriers suggested from survey responses were the lack of general HIV prevention information in Braille formats or sign language interpretation, for example.

Teachers also expressed some discomfort and embarrassment in having to talk about issues of sex. This is, of course, an issue for all sex education, in that it involves talking 
about topics that are of an explicit and otherwise private nature. However, there may be a particular challenge here in educating some people with disabilities, learning disabilities in particular, where messages which can sometimes be assumed (or "taken for granted" as one participant described), have to be made concrete and clear.

There is also some indication that there is not a consensus of agreement as to the provision of HIV prevention programmes, with staff disagreeing on what is appropriate and inappropriate for the young people they teach. There are reports of some anxiety about being seen to be promoting sexual activity. This may present a particular anxiety in the case of disabled learners who may be at increased vulnerability to sexual abuse and rape, or learners with learning disabilities who are construed as being unable to inhibit their sexuality and thus are "oversexed" [5]. With the need to consider issues of vulnerability, educators may be anxious about recognising the need for sex education, but worry that providing sex education might be harmful.

What is clear, is that more research is needed as to the efficacy of such HIV prevention education for people with disabilities. It is also important to note that people with disability are a vastly heterogenous population with varying levels of disabilities and capabilities. As the HIV and AIDS and STI Strategic Plan for South Africa 2007-2011 [25] suggests, there is a need for HIV prevention education to be specifically customized to the needs of the specific population. A general programme, which is included as part of a general curriculum and generally tailored to "mainstream" schools, would need to be adapted according to specific needs and disabling barriers faced. This does not only 
involve teaching material which allows for suitable forms of communication for different types of disabilities, but also consideration of the anxiety that disability and issues of vulnerability raises for educators.

\section{Declaration of Interests}

The financial assistance of the National Research Foundation (NRF) towards this research is hereby acknowledged. Opinions expressed and conclusions arrived at, are those of the author and are not necessarily to be attributed to the NRF. Participation by SINTEF was funded through a joint NRF/Norwegian Research Council program South Africa - Norway Programme on Research Cooperation.

\section{REFERENCES}

[1] Groce NE. HIV/AIDS and people with disability. Lancet 2003; 361:1401-1402.

[2] Groce NE. HIV/AIDS and individuals with disability. Health and Human Rights $2005 ; 8(2): 215-224$.

[3] Rohleder P, Braathen SH, Swartz L, Eide AH. HIV/AIDS and disability in southern Africa: a review of relevant literature. Disability and Rehabilitation 2009;31(1):51 - 59. [4] Milligan MS, Neufeldt AH. The myth of asexuality: A survey of social and empirical evidence. Sexuality and Disability 2001;19(2): 91-109.

[5] Craft A. (1987). Mental handicap and sexuality: Issues for individuals with a mental handicap, their parents and professionals. In: Craft A, editor. Mental handicap and sexuality: issues and perspectives. Kent: Costello, 1987, p.13-33.

[6] Sullivan PM, Knutson JF. Maltreatment and disabilities: A population-based epidemiological study. Child Abuse \& Neglect 2000; 24(10): 1257-1273. 
[7] Rohleder P, Swartz L. Providing sex education to persons with learning disabilities in the era of HIV/AIDS: Tensions between discourses of human rights and restriction. Journal of Health Psychology 2009;14(4):601-610

[8] Philander JH, Swartz L. Needs, barriers, and concerns regarding HIV prevention among South Africans with visual impairments: A key informant study. Journal of Visual Impairment and Blindness 2006;100:111-115.

[9] Wazakili M, Mpofu R, Devlieger P. Experiences and perceptions of sexuality and HIV/AIDS among young people with physical disabilities in a South African township: A Case study. Sexuality and Disability 2006;24:77-88.

[10] Bat-Chava Y, Martin D, Kosciw JG. Barriers to HIV/AIDS knowledge and prevention among deaf and hard of hearing people. AIDS Care 2005;17(5):623-634.

[11] Yousafzai AK, Dlamini PJ, Groce N, Wirz S. Knowledge, personal risk and experiences of HIV/AIDS among people with disabilities in Swaziland. International Journal of Rehabilitation Research 2004;27(3):247-251.

[12] Rohleder P, Swartz L, Schneider M, Groce N, Eide AH. HIV/AIDS and disability organizations in South Africa. AIDS Care 2010;22(2):221-227.

[13] Maart S, Jelsma J. The sexual behaviour of physically disabled adolescents. Disability and Rehabilitation 2010;32(6):438-443.

[14] Mulindwa IN. Study on reproductive health and HIV/AIDS among persons with disabilities in Kampala, Katakwi and Rakai districts (knowledge, attitudes and practices). Disabled Women's Network and Resource Organization. 2002. Available from: http://v1.dpi.org/lang-en/resources/details.php?page=355. Accessed August 14, 2007. 
[15] Munthali A, Mvula P, Ali S. Effective HIV/AIDS and reproductive health information to people with disabilities: A final report. Centre for Social Research: University of Malawi. 2004. Available from: www.dpi.org/en/resources/documents/FinalReportforFedomaStudyOctober2004.doc. Accessed June 25, 2005.

[16] Nosek MA, Howland C, Rintala DH, Young ME, Chanpong GF. National study of women with physical disabilities: Final report. Sexuality and Disability 2001;19(1):5-39. [17] Eide AH, Schür C, Ranchod C, Rohleder P, Swartz L, Schneider M. Level of knowledge and access to HIV prevention and services among individuals with disabilities in South Africa. AIDS Care (under review) [18] Birch DA, Angermeier LK, Gentsch DK. HIV Prevention education for students with mental retardation. Rural Special Education Quarterly 2002;21(3):15-20. [19] Yousafzai AK, Edwards K, D’Allesandro C, Lindström L. HIV/AIDS information and services: The situation experienced by adolescents with disabilities in Rwanda and Uganda. Disability and Rehabilitation 2005;27(22):1357-1363.

[20] Visser MJ, Schoeman JB, Perold JJ. Evaluation of HIV/AIDS prevention in South African schools. Journal of Health Psychology 2004;9(2):263-280.

[21] Kelly K, Ntlabati P, Oyosi S, van der Riet M, Parker W. Making HIV/AIDS our problem: Young people and the development challenge in South Africa. Centre for AIDS Development, Research and Evaluation (CADRE). 2002. Available from: www.cadre.org.za/pdf/Making AIDS our problem.pdf. Accessed March 12, 2005. [22] Groce NE. HIV/AIDS and disability: Capturing hidden voices, Report of the World Bank Yale University Global Survey of HIV/AIDS and Disability. Washington: World 
Bank. 2004. Available from:

http://siteresources.worldbank.org/DISABILITY/Resources/Health-and-

Wellness/HIVAIDS.pdf. Accessed March 12, 2005.

[23] Mangione T W. Mail surveys: Improving the quality. Thousand Oaks: Sage

Publications, 1995.

[24] Boyatzis RE. Transforming qualitative information: Thematic analysis and code development. California: Sage Publications, 1998.

[25] Department of Health. HIV and AIDS and STI strategic plan for South Africa, 2007-2011 (Draft 9). Pretoria: Department of Health, 2007. Available from:

http://www.doh.gov.za/docs/hivaids-progressrep.html 
Table 1: Type of disability served by LSEN schools

\begin{tabular}{|c|c|c|}
\hline Disability Type & $\begin{array}{c}\text { Frequency } \\
(N=34)\end{array}$ & Percent \\
\hline Intellectually Disabled & 26 & 76.5 \\
\hline Multiply Handicapped $^{1}$ & 18 & 52.9 \\
\hline Epilepsy & 16 & 47.1 \\
\hline Physically Disabled & 15 & 42.9 \\
\hline Deaf/Hard of Hearing & 13 & 38.2 \\
\hline Chronic Disease & 8 & 23.5 \\
\hline Blind/Low Vision & 5 & 14.7 \\
\hline Mentally Ill & 3 & 8.8 \\
\hline Haemophilia & 3 & 8.8 \\
\hline All Disability Groups ${ }^{2}$ & 2 & 5.9 \\
\hline Other & 6 & 17.6 \\
\hline
\end{tabular}

${ }^{T}$ This refers to people who may have 2 or more types of disabilities (e.g. Deaf and physically disabled

${ }^{2}$ This refers to schools that cater for all types of disabilities. 
Table 2: Perceptions of the number of people with disabilities reached by general HIV prevention messages

\begin{tabular}{|c|c|c|}
\hline Number of people reached & $\begin{array}{l}\text { Frequency } \\
(N=31)^{a}\end{array}$ & $\begin{array}{c}\text { Percent } \\
\text { Of total sample }(N=34)\end{array}$ \\
\hline None & 6 & 17.6 \\
\hline Few & 4 & 11.8 \\
\hline Some & 5 & 14.7 \\
\hline Most & 9 & 26.5 \\
\hline All & 3 & 8.8 \\
\hline Do not know & 4 & 11.8 \\
\hline
\end{tabular}

${ }^{\mathrm{a}}$ Three respondents did not give a response 
Table 3: Perceptions of why large HIV/AIDS campaigns have been inaccessible

\begin{tabular}{|c|c|c|}
\hline & $\begin{array}{l}\text { Frequency } \\
\qquad(N=31)^{a}\end{array}$ & $\begin{array}{l}\text { Percent } \\
\text { of total sample } \\
(N=34)\end{array}$ \\
\hline $\begin{array}{l}\text { Because they were complex materials } \\
\text { inappropriate for intellectually disabled }\end{array}$ & 23 & 67.6 \\
\hline $\begin{array}{l}\text { Because they were other written materials } \\
\text { (and thus inaccessible to the blind or those } \\
\text { unable to read) }\end{array}$ & 11 & 32.4 \\
\hline $\begin{array}{l}\text { Because they were Television Programs } \\
\text { (and thus inaccessible to the blind) }\end{array}$ & 7 & 20.6 \\
\hline $\begin{array}{l}\text { Because they were Radio Programs (and } \\
\text { thus inaccessible to the deaf) }\end{array}$ & 6 & 17.6 \\
\hline Training/Education sessions in which no & & \\
\hline $\begin{array}{l}\text { sign language or captioning was available } \\
\text { for those who are deaf }\end{array}$ & 6 & 17.6 \\
\hline $\begin{array}{l}\text { Because they were Billboards (and thus } \\
\text { inaccessible to the blind) }\end{array}$ & 5 & 14.7 \\
\hline $\begin{array}{l}\text { Training/Education session locations not } \\
\text { accessible by wheelchair }\end{array}$ & 4 & 11.8 \\
\hline Other ways & 1 & 2.9 \\
\hline
\end{tabular}

${ }^{\mathrm{a}}$ Three respondents did not give a response 